\title{
Predictors of Left Atrial Thrombus and Short-Term Recurrence of Arrhythmia in Patients Undergoing Electrical Cardioversion for Atrial Fibrillation, a Single-Centre Experience
}

\author{
Callan Gavaghan
}

The Gold Coast University Hospital, Hospital Boulevard

Southport 4215, Australia.

\begin{abstract}
${ }^{*}$ Corresponding author
Callan Gavaghan, The Gold Coast University Hospital, Hospital Boulevard, G216/154 Musgrave Avenue Southport QLD, 4215 Australia, Tel: +61431665288;

E-mail: cbgavaghan@hotmail.com
\end{abstract}

Submitted: 17 July 2017; Accepted: 29 July 2017; Published: 08 Sep 2017

\begin{abstract}
Background: Systemic thromboembolism is a serious complication of electrical cardioversion. Even in the absence of such complications there exists a significant rate of arrhythmia recurrence post cardioversion.
\end{abstract}

Aims: The aim of this study was to identify factors that may aid clinicians in identifying those patients at increased risk of atrial thrombus formation and short-term arrhythmia recurrence.

Methods: One-hundred and twelve patients were retrospectively identified across a 2.5 year period as having undergone electrical cardioversion at the Gold Coast University Hospital for atrial fibrillation or atrial flutter. Demographic, clinical and echocardiogram data was analysed to identify potential predictors of thrombus, unsuccessful cardioversion and arrhythmia recurrence.

Results: Cardioversion was successful in $87.6 \%$ of patients. Cardioversion was more successful initially in males ( $p<0.01)$ and those with reduced atrial volume $(p<0.01)$ and higher left ventricular ejection fraction $(p<0.01)$.

Arrhythmia recurrence within 3 months occurred in 57.7\% of patients. Recurrence was more likely in those with congestive heart failure $(p<0.05)$ and a longer pre-cardioversion duration of arrhythmia $(p<0.05)$.

Spontaneous echo contrast was observed in 3 (2.6\%) of patients, whilst left atrial thrombus was observed in 7 (6.2\%) of patients. Potential predictors of thrombus were congestive heart failure $(p<0.05)$ and increased left atrial volume $(p<0.01)$.

Conclusions: This retrospective study identified a number of factors that may useful in the clinical setting in predicting cardioversion success, both initially and short-term, in addition to predicting thrombus formation.

Keywords: Cardioversion, Thrombus, Atrial fibrillation, TOE, Echo.

\section{Introduction}

Atrial fibrillation (AF) is the most commonly identified arrhythmia in clinical practice and it is associated with significant morbidity and mortality [1]. Up to $15 \%$ of all ischaemic strokes can be attributed to underlying AF [2]. Direct-current cardioversion (DCCV) is a procedure that is performed with the goal of improving cardiovascular function and preventing thromboembolism [3]. However, there exists a significant risk of systemic thromboembolism, in up to $7 \%$ of patients, post DCCV [4-7]. This risk is reduced, but not removed entirely, by anticoagulating patients for approximately 3-4 weeks prior to DCCV [5-8]. Historically this was achieved using Warfarin, but newer oral anticoagulants, in particular Rivaroxaban, are now often used for this purpose [9]. Studies have suggested that despite adequate anticoagulation left atrial thrombus (LAT) and spontaneous echo contrast (SEC) may persist in 2-12\% of patients [10-13].

Trans-oesophageal echocardiography (TOE) is routinely used prior to DCCV to exclude the presence of LAT, left atrial appendage thrombus (LAAT), sludge and SEC [14]. The ability to detect these factors is significant as they are all associated with an increased risk of embolic stroke post DCCV [15]. Studies such as the ACUTE trial, have suggested that TOE-guided cardioversion may be as effective as conventional anticoagulation in preventing embolic events post DCCV [16].

The risk of ischaemic stroke in AF ranges widely depending on the use of anticoagulation, co morbid conditions and previous stroke history $[17,18]$. The CHADS2 and CHA2DS2-VASc scores are simple scoring systems that can be used to categorise a patient's risk of an ischaemic event secondary to atrial fibrillation. Recent 
studies have demonstrated that there may be a role for this scoring system in predicting the presence of spontaneous echo contrast (SEC) or thrombus on a pre-DCCV TOE $[19,20]$.

Kleemann, et al. noted, however, that the CHA2DS2-VASc score does not incorporate echocardiographic findings and have attempted to use these measurements as a tool for assessing the risk of embolic events post cardioversion. Recent studies have published findings indicating that there may be several clinical and echocardiographic factors associated with the presence of thrombus, such as increased left atrial diameter, heart failure, duration of $\mathrm{AF}$, and reduced left ventricular ejection fraction (LVEF) [12,21-23].

In addition to considering the risks of DCCV for AF, it is worth noting the success rates and clinical benefit achieved using this procedure. Documented long-term success rates post DCCV, where success is defined as maintaining a sinus rhythm, vary from 34-60\%. Several studies have attempted to identify potential predictors of successful DCCV, such as the absence of congestive heart failure, short duration of AF prior, or lower left atrial volume. Identifying these potential predictive factors is of clinical importance as they may be used to guide a physician's decision making in the management of patients in $\mathrm{AF}$ [24-31].

This present study will build on current knowledge by focusing on data collected from patients undergoing elective DCCV for AF or atrial flutter (AFL) over a 2.5-year period within a single centre. We will be assessing the data to identify the patient variables that are predictive of thrombus. We will also be discussing the factors that are predictive of cardioversion success, both initially and at follow-up. Further clarifying these factors may of use in dictating the appropriateness of performing DCCV for AF and AFL in certain patient populations.

\section{Material and methods}

Patient Population

We retrospectively identified 112 consecutive patients ( $75 \%$ male) as having attended for TOE-guided DCCV for AF or AFL at the Gold Coast University Hospital, and its predecessor the Gold Coast Hospital, between January 2013 and July 2015. In total 107 TOEguided DCCVs were performed during this period. Three patients did not undergo DCCV due to persistent LAT on TOE and a further 2 patients self-reverted after having their DCCV postponed due to LAT seen on initial TOE.

\section{Data Collection}

A database of all patients who were booked for TOE-guided DCCV was compiled and medical records and imaging databases were retrospectively reviewed. There was a particular focus on obtaining data relevant to predicting LAAT/SEC and DCCV success, in addition to collecting information regarding procedural and postprocedural complications. Demographic data, patient co-morbidities, transthoracic echocardiogram (TTE) and TOE parameters, data pertaining to previous DCCV and success of DCCV were collated. The CHA2DS2-VASc score was calculated for each patient based on data pertaining to presence of heart failure, hypertension, patient age, diabetes, sex, previous stroke and vascular disease. Maintenance of sinus rhythm post DCCV was assessed via outpatient notes and correlated with follow-up ECGs in the medical record. Without continuous cardiac monitoring it would be difficult to rule out the return of paroxysmal AF post DCCV. It was assumed in this study that if a patient remained asymptomatic post DCCV, and had sinus rhythm at followup, that they had not reverted to AF.

Post-procedural complications such as thromboembolism were also noted by assessing medical records.

\section{Definitions}

Cardioversion success was defined as an immediate return to sinus rhythm after DCCV. Long-term cardioversion success was defined as maintenance of sinus rhythm more than 3 months after DCCV. Failed cardioversion refers to patients who either did not revert to sinus rhythm at any time or those who returned to AF or AFL within several minutes of DCCV. LAAT and LAT were defined, as per Wazni et al. and Grewal et al., as a circumscribed and uniformly dense mass, distinct from the left atrium and left atrial appendage endocardium, that is present in more than 1 imaging plane $[32,33]$. SEC was defined as smoke-like echoes with a clear swirling pattern. In this study the findings of SEC, LAAT or LAT are summated under the term 'thrombus'. Excess alcohol consumption was defined as the consumption of more than 2 standard drinks per day, in keeping with Australian NHMRC guidelines [34].

\section{Echocardiography}

All echocardiographic examinations were performed at $\mathrm{GCH}$ or GCUH. All patients had a TOE examination assessing for presence of thrombus prior to DCCV. Ninety-percent $(n=100)$ of patients also had a TTE in the 4 weeks prior to DCCV. Measurements of ejection fraction and atrial volume were noted at that time.

\section{Procedure Description}

All patients received a minimum of 3 weeks anticoagulation preTOE with warfarin, apixaban or rivaroxaban. Patients were generally sedated with propofol and midazolam by an attending anaesthetist. Pre-DCCV TOE was then performed. If no thrombus was present on TOE then the treating team would proceed with DCCV. The amount of electricity used for cardioversion was variable depending upon patient body habitus and attending cardiologist decision. The maximum amount of electricity applied in a single shock was 200J bi-phasic and the minimum was 50J bi-phasic. If cardioversion was not achieved on the first shock then up to 2 further shocks were applied. The procedure was abandoned if cardioversion was not achieved after 3 shocks.

\section{Statistics}

Data was analysed using the SPSS (SPSS Inc., Chicago USA) and MedCalc (Mariakerke, Belgium) software. The Student's t-test was used to calculate $p$-values for continuous variables with a normal distribution and Mann-Whitney U-test was used for continuous variables outside the normal distribution. For categorical variables either the Fisher's exact test or the Chi-square test was applied. Receiver operating characteristic (ROC) curves were then used to demonstrate the sensitivities and specificities of variables predictive of thrombus or cardioversion success.

\section{Results}

In the current study, 112 patients undergoing TOE DCCV were included as study participants. As (Table 1) reveals, the majority $(50.0 \%)$ of the study population were between the ages of 61 and 75. The mean age of the study sample was $63 \pm 25$ years. Of the total subjects, $75 \%$ were males and $25 \%$ were females. Following 
TOE, $8.9 \%$ of patients were identified as having thrombus in the left atrium. Of the patients in this study, $13(11 \%)$ had AFL, whilst the remainder had AF. The mean BMI of the study sample was $30.51 \pm$ $14 \mathrm{Kg} / \mathrm{m}^{2}$. It was observed that $71.3 \%$ of study subjects were either overweight or obese (BMI $\geq 25)$. The mean CHA2DS2-VASc score was found to be $1.92 \pm 2.8$.

Table 1: Clinical and Demographic Profile

\begin{tabular}{|c|c|}
\hline Parameter & Value (\%) \\
\hline$<46$ & $9(8.1)$ \\
\hline $46-60$ & $30(26.8)$ \\
\hline $61-75$ & $56(50)$ \\
\hline$>76$ & $17(15.2)$ \\
\hline \multirow[t]{2}{*}{ Gender } & $84(75)$ \\
\hline & $28(25)$ \\
\hline \multicolumn{2}{|l|}{$\mathrm{BMI} \uparrow\left(\mathrm{kg} / \mathrm{m}^{2}\right)$} \\
\hline$<18.5$ (Underweight) & $0(0)$ \\
\hline 18.5-24.9 (Healthy Weight) & $14(12.5)$ \\
\hline 25-29.9 (Over Weight) & $38(33.9)$ \\
\hline 30-34.9 (Obesity) & $24(21.4)$ \\
\hline 35-39.9 (Obesity) & $10(8.9)$ \\
\hline$\geq 40$ (Extreme Obesity) & $8(7.1)$ \\
\hline LAAT/LAT $!$ & $5(4.5)$ \\
\hline SEC $\S$ & $5(4.5)$ \\
\hline Atrial Fibrillation & $99(88.4)$ \\
\hline Atrial Flutter & $13(11.6)$ \\
\hline $\mathrm{CHF} \Phi$ & $21(18.8)$ \\
\hline Hypertension & $46(41.1)$ \\
\hline Diabetes & $10(8.9)$ \\
\hline Prior History of Stroke or TIA $\dagger \dagger$ & $7(6.3)$ \\
\hline Valvular Heart Disease & $54(48.2)$ \\
\hline Excess Alcohol Consumption & $9(8)$ \\
\hline
\end{tabular}

$\uparrow$ BMI-Body Mass Index Kg/m², tLAAT/LAT-Left Atrial Appendage Thrombus/Left Atrial Thrombus, §SEC-Spontaneous Echo Contrast, -CHF-Congestive Heart Failure $\uparrow \dagger$ TIA-Transient Ischemic Attack

Reversion to sinus rhythm post-DCCV was observed in $94(87.6 \%)$ patients and it was unsuccessful in $13(12.4 \%)$ patients. The potential predictors of successful cardioversion are included in (Table 2). Following comparison of these two groups, it was found that unsuccessful cardioversion was significantly more likely amongst females $(61.5 \%, p<0.01)$ and those patients with higher Left Atrial Volume-Biplane (LAV-BP) $(\mathrm{p}<0.01)$ and lower Left Ventricular Ejection Fraction-Biplane (LVEF-BP) $(\mathrm{p}<0.01)$.

Cardioversion was more successful amongst those with previous history of cardioversion $(27.7 \%, \mathrm{p}<0.05)$.
Table 2: Predictors of Successful Cardioversion

\begin{tabular}{|l|c|c|c|}
\hline \multicolumn{1}{|c|}{ Parameter } & $\begin{array}{l}\text { Successful } \\
\text { Cardioversion } \\
\text { (n=94) }\end{array}$ & $\begin{array}{l}\text { Unsuccessful } \\
\text { Cardioversion } \\
(\mathbf{n = 1 3 )}\end{array}$ & P-value \\
\hline Age (Years) & $63.9 \pm 12.0$ & $59.8 \pm 15.9$ & $0.27^{\mathrm{a}}$ \\
\hline Female & $18(19.9)$ & $8(61.5)$ & $0.04^{\mathrm{b}}$ \\
\hline BMI† $\left(\mathrm{kg} / \mathrm{m}^{2}\right)$ & $29.9 \pm 5.9$ & $34.9 \pm 12.03$ & $0.15^{\mathrm{c}}$ \\
\hline $\begin{array}{l}\text { Duration of AF/AFL } \\
\text { (weeks) }\end{array}$ & $75.7 \pm 122$ & $77.1 \pm 70.3$ & $0.78^{\mathrm{c}}$ \\
\hline $\begin{array}{l}\text { Previous History of } \\
\text { cardio version }\end{array}$ & $26(27.7)$ & $0(0)$ & $0.03^{\mathrm{d}}$ \\
\hline Hypertension & $41(43.6)$ & $4(30.8)$ & $0.62^{\mathrm{b}}$ \\
\hline Diabetes & $10(10.6)$ & $0(0)$ & $0.60^{\mathrm{d}}$ \\
\hline CHF§ & $16(17.1)$ & $2(15.4)$ & $0.96^{\mathrm{d}}$ \\
\hline Valvular Heart Disease & $46(46.1)$ & $5(38.5)$ & $0.74 \mathrm{~b}$ \\
\hline Vascular Diseases & $19(20.4)$ & $2(15.4)$ & $0.87^{\mathrm{d}}$ \\
\hline $\begin{array}{l}\text { Excess Alcohol } \\
\text { Consumption }\end{array}$ & $8(8.5)$ & $1(7.7)$ & $0.98^{\mathrm{d}}$ \\
\hline Atrial Flutter & $13(13.8)$ & $0(0)$ & $0.35^{\mathrm{d}}$ \\
\hline Previous History of Stroke & $5(5.3)$ & $2(15.4)$ & $0.68^{\mathrm{d}}$ \\
\hline CHADS2VASc & $1.9 \pm 1.4$ & $2.0 \pm 1.6$ & $0.90^{\mathrm{c}}$ \\
\hline $\begin{array}{l}\text { Left Atrial Volume-Indexed } \\
\left(\mathrm{mL} / \mathrm{m}^{2}\right)\end{array}$ & $37.8 \pm 20.0$ & $43.6 \pm 15.3$ & $0.10^{\mathrm{c}}$ \\
\hline $\begin{array}{l}\text { Left Atrial Volume-Biplane } \\
\left(\mathrm{mL} / \mathrm{m}^{2}\right)\end{array}$ & $61.9 \pm 17.7$ & $88.7 \pm 29.3$ & $0.001^{\mathrm{a}}$ \\
\hline LVEF-Biplane $(\%)$ & $60.0 \pm 9.7$ & $50.5 \pm 12.0$ & $0.007^{\mathrm{a}}$ \\
\hline
\end{tabular}

$(\%)$, mean \pm standard deviation

$\uparrow$ BMI-Body Mass Index Kg/m² $\ddagger$ Atrial Fibrillation/Atrial Flutter, $\S \mathrm{CHF}-$ Congestive Heart Failure, |LVEF- Left Ventricular Ejection Fraction

$\mathrm{a}=$ Unpaired $\mathrm{t}$ Test

$\mathrm{b}=$ Pearson Chi Square Test

$\mathrm{c}=$ Mann Whitney Test

$\mathrm{d}=$ Fischer Exact Test

Following echocardiography SEC was observed in $3(2.7 \%)$ of patients and LAT or LAAT was observed in 7 (6.3\%) of patients, while $102(91.0 \%)$ patients did not show any evidence of atrial thrombus/SEC. Initial cardioversion was abandoned in all patients with SEC or LAAT/LAT until a delayed repeat TOE concluded these findings were no long present. (Table 3) shows the potential predictors of thrombus formation. The rate of congestive heart failure (CHF) was significantly higher amongst those patients who demonstrated thrombus $(\mathrm{p}<0.05)$. LAV-Indexed and LAV-BP were significantly higher amongst patients with atrial thrombus $(\mathrm{p}=$ 0.01 and $\mathrm{p}<0.001$ respectively). 
Table 3: Predictors of Thrombus

\begin{tabular}{|l|c|c|c|}
\hline \multicolumn{1}{|c|}{ Parameter } & $\begin{array}{l}\text { Thrombus/ } \\
\text { SEC Present } \\
(\mathbf{n}=\mathbf{1 0})\end{array}$ & $\begin{array}{l}\text { Thrombus/ } \\
\text { SEC Absent } \\
\text { (n= 102) }\end{array}$ & P-Value \\
\hline Age (Years) & $66.7 \pm 13.0$ & $63.0 \pm 12.3$ & $0.36^{\mathrm{a}}$ \\
\hline Female & $3(30.0)$ & $25(24.5)$ & $0.70^{\mathrm{d}}$ \\
\hline BMI† $\left(\mathrm{Kg} / \mathrm{m}^{2}\right)$ & $28.4 \pm 5.3$ & $30.8 \pm 7.1$ & $0.39^{\mathrm{c}}$ \\
\hline $\begin{array}{l}\text { Duration of } \\
\text { AFł (weeks) }\end{array}$ & $38.5 \pm 70.3$ & $75.3 \pm 118.0$ & $0.96^{\mathrm{c}}$ \\
\hline $\begin{array}{l}\text { Previous History of } \\
\text { Cardioversion }\end{array}$ & $1(10)$ & $35(22.2)$ & $0.16^{\mathrm{d}}$ \\
\hline $\begin{array}{l}\text { Number of Shocks to } \\
\text { Cardiovert }\end{array}$ & $1 \pm 0$ & $1.4 \pm 0.7$ & $0.84 \mathrm{c}$ \\
\hline CHF§ & $5(50.0)$ & $16(15.7)$ & $0.02^{\mathrm{b}}$ \\
\hline Valvular Heart Disease & $5(50.0)$ & $49(48.0)$ & $0.51^{\mathrm{b}}$ \\
\hline Vascular Diseases & $0(0)$ & $21(20.8)$ & $0.11^{\mathrm{d}}$ \\
\hline $\begin{array}{l}\text { Excess Alcohol } \\
\text { Consumption }\end{array}$ & $0(0)$ & $9(8.8)$ & $0.41^{\mathrm{d}}$ \\
\hline Atrial Flutter & $1(10.0)$ & $12(11.8)$ & $0.67^{\mathrm{d}}$ \\
\hline Previous History of Stroke & $0(0)$ & $7(6.9)$ & $0.50^{\mathrm{d}}$ \\
\hline CHADS2VASc & $2.1 \pm 1.3$ & $1.9 \pm 1.5$ & $0.60^{\mathrm{c}}$ \\
\hline $\begin{array}{l}\text { Left Atrial Volume-Indexed } \\
\left.\text { (mL/m }{ }^{2}\right)\end{array}$ & $56.5 \pm 12.3$ & $41.9 \pm 15.6$ & $0.01^{\mathrm{c}}$ \\
\hline $\begin{array}{l}\text { Left Atrial Volume-Biplane } \\
\left.\text { (mL/m }{ }^{2}\right)\end{array}$ & $104 \pm 18.8$ & $52.0 \pm 12.2$ & $<0.001^{\mathrm{a}}$ \\
\hline LVEF-Biplane $\%)$ & $55.4 \pm 10.5$ & $52.0 \pm 12.2$ & $0.11^{\mathrm{a}}$ \\
\hline
\end{tabular}

$(\%)$, mean \pm standard deviation

$\uparrow$ BMI-Body Mass Index $\mathrm{Kg} / \mathrm{m}^{2}$, $₫$ Atrial Fibrillation/Atrial Flutter, $\S$ CHF-Congestive Heart Failure, $\dagger+$ LVEF-Left Ventricular Ejection Fraction

$\mathrm{a}=$ Unpaired $\mathrm{t}$ Test

$\mathrm{b}=$ Pearson Chi Square Test

$\mathrm{c}=$ Mann Whitney Test

$\mathrm{d}=$ Fischer Exact Test

It was observed that $56(57.7 \%)$ patients had recurrence of arrhythmia within 3 months following successful initial cardioversion. Those with AFL and CHF were significantly less likely $(\mathrm{p}<0.05)$ to have a recurrence of arrhythmia. The duration of AF was also found to be significantly longer in those with recurrence of arrhythmia $(p<0.05)$. The analysis of potential predictors of arrhythmia recurrence is shown in (Table 4).
Table 4: Predictors of Post Cardioversion recurrence of Arrhythmia

\begin{tabular}{|c|c|c|c|}
\hline Parameter & $\begin{array}{l}\text { Recurrence of } \\
\text { Arrhythmia } \\
(\mathbf{n}=\mathbf{5 6})\end{array}$ & $\begin{array}{l}\text { Non-recurrence } \\
\text { of Arrhythmia } \\
(n=41)\end{array}$ & P-Value \\
\hline Age (Years) & $62.9 \pm 12.3$ & $64.2 \pm 13.7$ & $0.62^{\mathrm{a}}$ \\
\hline Female & $15(26.8)$ & $9(22.0)$ & $0.98^{\mathrm{b}}$ \\
\hline $\mathrm{BMI} \dagger\left(\mathrm{Kg} / \mathrm{m}^{2}\right)$ & $31.0 \pm 7.6$ & $30.6 \pm 6.7$ & $0.79^{\mathrm{c}}$ \\
\hline Duration of AF $\$$ (weeks) & $74 \pm 99.7$ & $59.4 \pm 113.2$ & $0.02^{\mathrm{c}}$ \\
\hline $\begin{array}{l}\text { Previous History of } \\
\text { Cardioversion }\end{array}$ & $14(25)$ & $8(19.5)$ & $0.69^{b}$ \\
\hline $\begin{array}{l}\text { Number of shocks to } \\
\text { Cardiovert }\end{array}$ & $1.4 \pm 0.7$ & $1.3 \pm 0.6$ & $0.72^{\mathrm{c}}$ \\
\hline $\mathrm{CHF} \S$ & $6(10.7)$ & $12(29.3)$ & $0.03^{\mathrm{b}}$ \\
\hline Valvular Heart Disease & $27(46.3)$ & $19(46.3)$ & $0.83^{\mathrm{b}}$ \\
\hline Vascular Diseases & $10(17.9)$ & $10(24.4)$ & $0.59^{\mathrm{b}}$ \\
\hline $\begin{array}{l}\text { Excess Alcohol } \\
\text { Consumption }\end{array}$ & $8(14.3)$ & $1(2.4)$ & $0.07^{\mathrm{d}}$ \\
\hline Atrial Flutter & $2(3.6)$ & $9(22.0)$ & $0.007^{\mathrm{d}}$ \\
\hline Previous History of Stroke & $5(8.9)$ & $1(2.4)$ & $0.39^{\mathrm{d}}$ \\
\hline CHADS2VASc & $1.8 \pm 1.4$ & $2.2 \pm 1.7$ & $0.34^{\mathrm{c}}$ \\
\hline $\begin{array}{l}\text { Left Atrial Volume-Index } \\
\left(\mathrm{mL} / \mathrm{m}^{2}\right)\end{array}$ & $43.0 \pm 16.3$ & $43.3 \pm 16.9$ & $0.85^{\mathrm{c}}$ \\
\hline $\begin{array}{l}\text { Left Atrial Volume-Biplane } \\
\left(\mathrm{mL} / \mathrm{m}^{2}\right)\end{array}$ & $86.0 \pm 31.0$ & $86.6 \pm 29.1$ & $0.91^{\mathrm{a}}$ \\
\hline LVEF-Biplane (\%) & $53.0 \pm 12.2$ & $49.7 \pm 12.6$ & $0.19^{\mathrm{a}}$ \\
\hline
\end{tabular}

$(\%)$, mean \pm standard deviation

$\uparrow$ BMI-Body Mass Index $\mathrm{Kg} / \mathrm{m}^{2}, \ddagger$ Atrial Fibrillation/Atrial Flutter, $\S \mathrm{CHF}-$ Congestive Heart Failure, $₫ \mathrm{LVEF}-$ Left Ventricular Ejection Fraction

$\mathrm{a}=$ Unpaired $\mathrm{t}$ Test

$\mathrm{b}=$ Pearson Chi Square Test

$\mathrm{c}=$ Mann Whitney Test

$\mathrm{d}=$ Fischer Exact Test

When LAV-BP and LEVF-BP. two predictors of initial successful cardio version, were compared in an ROC curve (Figure 1), the area under the curve for LAV-BP and LVEF-BP was $0.716 \pm 0.18$ and $0.352 \pm 0.20$ respectively.

Figure 1: ROC curve showing LAV $\uparrow$-Biplane and LVEF + -Biplane as predictor of Initial Successful Cardioversion

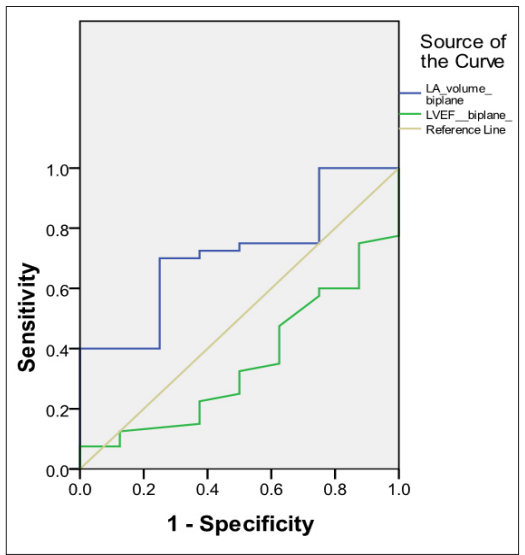




\begin{tabular}{|l|c|c|}
\hline & LAV-Biplane & LVEF-Biplane \\
\hline Area under Curve & 0.716 & 0.352 \\
\hline Standard Error & 0.090 & 0.098 \\
\hline Level of Significance & 0.056 & 0.189 \\
\hline $\begin{array}{l}\text { 95\% Confidence } \\
\text { Interval }\end{array}$ & $0.539-0.892$ & $0.160-0.534$ \\
\hline
\end{tabular}

$\dagger$ LAV-Left Atrial Volume, $\$$ LVEF-Left Ventricular Ejection Fraction

An ROC curve showing LA-BP and LVEF as predictors of atrial thrombus/SEC was performed (Figure 2). This revealed an area under the curve of $0.662 \pm 0.14$ and $0.592 \pm 0.18$ for LA-BP and LVEF respectively.

Figure 2: ROC curve showing LA $\dagger$-Biplane and LVEFț as predictors of atrial thrombus

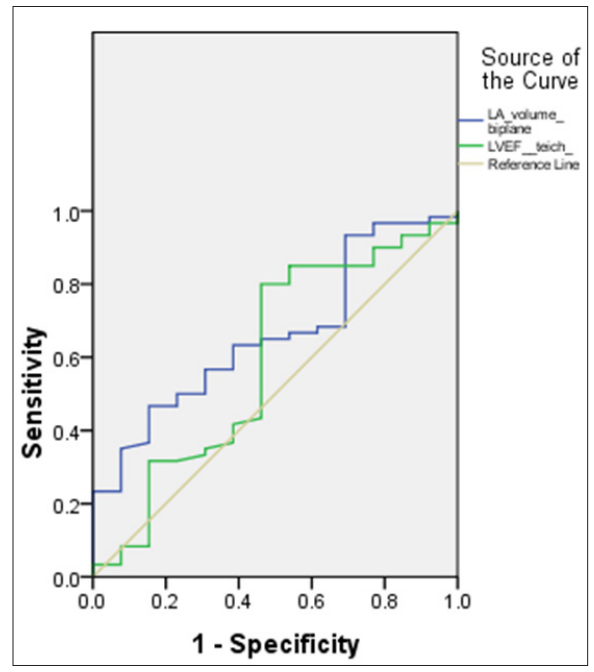

\begin{tabular}{|l|c|c|}
\hline & LA Volume- BP & LVEF \\
\hline Area under Curve & 0.662 & 0.592 \\
\hline Standard Error & 0.077 & 0.097 \\
\hline Level of Significance & 0.068 & 0.303 \\
\hline $\begin{array}{l}\text { 95\% Confidence } \\
\text { Interval }\end{array}$ & $0.512-0.812$ & $0.402-0.782$ \\
\hline
\end{tabular}

$\dagger$ LAV-Left Atrial Volume, $\$$ LVEF-Left Ventricular Ejection Fraction

\section{Procedural Complications}

Procedural complications arising from DCCV were generally rare. Four patients experienced an episode of hypotension post procedure, but no acute medical intervention was required for this. One elderly patient died from a stroke 4 months post DCCV. No thrombus was noted at the time of DCCV and the patient had remained in sinus rhythm at 2 months post DCCV. A second patient, who had an unsuccessful DCCV, was noted to have a TIA 3 month's post procedure.

\section{Discussion}

This study of TOE DCCV performed in 112 patients, from a single tertiary hospital in Australia, demonstrates immediate and short-term success similar to published studies on this subject. Cardioversion resulted in an initial return to sinus rhythm in $87.6 \%$ of patients in this study, while the published immediate success rate ranges from $82-94.5 \%[25,27,35,36]$. Amongst those with an initially successful cardioversion, sinus rhythm was maintained after 3 months in $57.7 \%$ of patients. In comparison, two studies with follow-up at only 1 month post DCCV reported success rates of $49 \%$ and $62.5 \%$ $[26,31]$.

Unsuccessful initial cardioversion was significantly more likely $(\mathrm{p}<0.05)$ in females, those having their first DCCV, and in patients with higher LAV-BP and decreased LVEF-BP. In the reviewed literature, patient sex generally had little significance on the success of cardioversion and some findings were contradictory. Kuppahally et al. found that cardioversion was more successful in females, whereas Akdemir et al. noted the opposite. Adjusting for patient co-morbidities may result in a lessening of this association, as it did in the former study [31,37].

As in this study, reduced biplane LAV was also noted to be a predictor of cardioversion success in several previous studies $[28,31]$. Interestingly, there was less correlation between indexed LAV than for biplane LAV ( $p=0.1$ vs. $p<0.001$ ). This is in keeping with the trend towards BMI being higher in those with unsuccessful cardioversion $(\mathrm{p}=0.15)$, where indexing a patient's LAV to their surface area would largely negate this effect. Likewise a previous study has shown DCCV to be initially more successful in those with a lower BMI [38]. The area under the curve (AUC) when using LAV-BP to predict cardioversion success was 0.716 . This result indicates that LAV-BP can be used in a clinical setting to predict initial cardioversion success with a fair level of accuracy. This information may be of use when considering whether to proceed with DCCV in certain patient populations.

It is a noteworthy finding that LVEF was significantly $(\mathrm{p}>0.007)$ higher in those patients who had successful cardioversion. In similar studies LVEF has not been significantly associated with DCCV success $[28,39]$. When LVEF-BP was plotted on a ROC curve, however, the AUC was 0.352, indicating that LVEF-BP is not a reliable test for predicting DCCV success.

Those patients undergoing their first DCCV were significantly more likely $(p>0.05)$ to be unsuccessful in cardioverting. This finding is likely due to selection bias, as all patients undergoing a repeat DCCV in this study had undergone an initially successful DCCV in the past.

The variables associated with reduced recurrence of arrhythmia three months post DCCV were the presence of heart failure, AFL and shorter duration of arrhythmia pre-DCCV $(p<0.05)$. A similar finding regarding AFL and the reduced incidence of arrhythmia recurrence post DCCV has been indicated by a previous study [40]. Conversely, CHF has in the past been associated with an increased likelihood of arrhythmia recurrence [30]. A limitation of this study was that the severity and management of the CHF was not noted, which limits the interpretation of this result [30].

Previous studies have also found that a longer duration of $\mathrm{AF}$ prior to DCCV is associated with a higher incidence of arrhythmia recurrence $[41,42]$. Indeed, in this current study those with $\mathrm{AF}$ duration $>24$ weeks pre-DCCV had a failure rate at 3 months postDCCV more than double those with AF duration $<24$ weeks $(55.5 \%$ 
vs. $20.5 \%$ ). Interestingly, the duration of AF was not significant in predicting the success of the initial cardioversion, despite previous studies indicating an association $[30,42]$.

There was a trend towards excess alcohol consumption being more common amongst those with arrhythmia recurrence than in those who remained in sinus rhythm $(p=0.07)$. This association has also been documented by previous studies and is in keeping with alcohol being a precipitant in the initial development of AF $[37,43]$.

The prevalence of LA thrombus in this study was $6.3 \%$, while the prevalence of SEC was $2.7 \%$. The published incidence for either of these findings on TOE ranges widely from $8.2 \%-57 \%$ $[15,21,22,23]$. There are a number of possible explanations for this, such as different protocols for anticoagulation pre-TOE, accuracy of ultrasound equipment and inter-observer variability in detecting and defining thrombus.

The three variables identified as being predictors for the presence of clot were CHF, increased LA volume-indexed and increased LA volume-BP. LA volume and LA diameter have both been identified as potential predictors of clot formation in previous studies [12,23]. LA enlargement (LAE) may occur either as a consequence of AF or, alternatively, it may promote the development of AF, such as in the setting of mitral valve disease $[44,45]$. Both AF and LAE contribute to abnormal blood stasis and place such patients at significant risk of thromoboembolic disease, therefore it is logical that LAE be positively associated with the presence of clot [45].

The increased incidence of clot in those patients with CHF was in keeping with the finding that LVEF was generally lower in those with clot on TOE. CHF has been identified by previous studies as an independent risk factor for clot formation $[46,47]$.

Despite CHF being predictive for thrombus, the CHA2DS2-VASc scores were not significantly different between those with clots and those without. It is notable however, that all patients with a thrombus also had a CHA2DS2-VASc score of $\geq 1$. There has been contention historically as to the usefulness of CHADS2 and CHA2DS2-VASc in excluding the presence of thrombus. While some studies have found a CHADS2 score of 0 to exclude thrombus, others have demonstrated that thrombus may persist despite low scores [21,48-50]. Although an increase in the CHA2DS2-VASc score may be associated with an increased likelihood of thrombus in certain populations, it does not directly incorporate other factors, such as LAE, that are predictive of thrombus.

\section{Limitation}

The limitations of this study are primarily those inherent to most retrospective studies. This study relies on medical records and procedural documents to obtain data. A prospective study would be preferable in ensuring completeness of pre-procedural and followup information. For instance, although all patients in this study had received anticoagulation pre-TOE, it is difficult to determine retrospectively whether this medication was properly administered and adhered to. To ensure accuracy in this study the TTE ideally would have been performed at the time of TOE-cardioversion. Unfortunately this was often performed around 2-4 weeks prior, which has implications on the data if any significant changes to cardiac function occurred during this time. Echocardiographic data was not re-analysed de novo by independent cardiologists so the presence of thrombus may be affected by the expertise of the cardiologist who initially reported the images. The authors chose not to utilise multivariate analysis in light of this method having a low level of power for a sample of this size. In a larger sample a multivariate analysis would be useful to discern if any of the independent variables are in fact co-dependant.

\section{Conclusions}

This single-centre, retrospective study, has identified a number of patient factors associated with reduced rates of DCCV success, both initially and within 3 months. Practitioners who take these factors into account may be better able to predict patient outcomes post procedure, which will aid in deciding whether DCCV is appropriate for certain populations. The predictors of thrombus formation discussed in this study may be used to categorize patients at high risk of thromboembolism, ensuring that anti-coagulation regimes are adhered to and that TOE is performed pre-DCCV.

\section{Acknowledgments}

The author acknowledges Dr Selvanayagam Niranjan, Cardiologist at The Gold Coast University Hospital, for his supervision of this study.

\section{References}

1. Demir K, Can I, Koc F, Ayhan S, Akilli H, et al. (2011) Atorvastatin given prior to electrical cardioversion does not affect the recurrence of atrial fibrillation in patients with persistent atrial fibrillation who are on antiarrhythmic therapy. Med Princ Pract 20: 464-469.

2. Fang MC, Go AS, Chang Y, Borowsky L, Pomernacki NK, et al. (2008) Comparison of risk stratification schemes to predict thromboembolism in people with nonvalvular atrial fibrillation. J Am Coll Cardiol 51: 810-815.

3. Corrado G, Santarone M, Beretta S, Tadeo G, Tagliagambe LM, et al. (2000) Early cardioversion of atrial fibrillation and atrial flutter guided by transoesophageal echocardiography: a single centre 8.5-year experience. Europace 2: 119-126.

4. Black IW, Fatkin D, Sagar KB, Khandheria BK, Leung DY, et al. (1994) Exclusion of atrial thrombus by transesophageal echocardiography does not preclude embolism after cardioversion of atrial fibrillation. A multicenter study. Circulation 89: 2509-2513.

5. Arnold AZ, Mick MJ, Mazurek RP, Loop FD, Trohman RG, et al. (1992) Role of prophylactic anticoagulation for direct current cardioversion in patients with atrial fibrillation or atrial flutter. J Am Coll Cardiol 19: 851-855.

6. Bjerkelund CJ, Orning OM (1969) The efficacy of anticoagulant therapy in preventing embolism related to D.C. electrical conversion of atrial fibrillation. Am J Cardiol 23: 208-216.

7. Weinberg DM, Mancini J (1989) Anticoagulation for cardioversion of atrial fibrillation. Am J Cardiol 63: 745-746.

8. Klein AL, Murray RD, Grimm RA (1997) Transesophageal echocardiography-guided cardioversion: going for broke? Ann Intern Med 127: 652-653.

9. Hicks T, Stewart F, Eisinga A (2016) NOACs versus warfarin for stroke prevention in patients with AF: a systematic review and meta-analysis. Open Heart 3: e000279.

10. Corrado G, Tadeo G, Beretta S, et al. (1999) Atrial thrombi resolution after prolonged anticoagulation in patients with 
atrial fibrillation. Chest 115: 140-143.

11. Kishima H, Mine T, Kodani T, Masuyama T (2015) Prediction of left atrial thrombi in patients with atrial tachyarrhythmias during warfarin administration: retrospective study in Hyogo College of Medicine. Heart Vessels 30: 331-337.

12. Sugiura S, Fujii E, Senga M, Sugiura E, Nakamura M, et al. (2012) Clinical features of patients with left atrial thrombus undergoing anticoagulant therapy. J Interv Card Electrophysiol 34: 59-63.

13. Saeed M, Rahman A, Afzal A, Agoston I, Jammula P, et al. (2006) Role of transesophageal echocardiography guided cardioversion in patients with atrial fibrillation, previous left atrial thrombus and effective anticoagulation. Int J Cardiol 113: 401-405.

14. Di Minno MN, Ambrosino P, Dello Russo A, Casella M, Tremoli E, et al. (2016) Prevalence of left atrial thrombus in patients with non-valvular atrial fibrillation. A systematic review and meta-analysis of the literature. Thromb Haemost 115: 663-677.

15. Lowe BS, Kusunose K, Motoki H, Varr B, Shrestha K, et al. (2014) Prognostic significance of left atrial appendage "sludge" in patients with atrial fibrillation: a new transesophageal echocardiographic thromboembolic risk factor. J Am Soc Echocardiogr 27: 1176-1183.

16. KleinAL, GrimmRA,BlackIW,LeungDY,Chung MK, etal.(1997) Cardioversion guided by transesophageal echocardiography: the ACUTE Pilot Study. A randomized, controlled trial. Assessment of Cardioversion Using Transesophageal Echocardiography. Ann Intern Med 126: 200-209.

17. Inoue $H$, Nozawa $T$, Hirai $T$ (2006) Accumulation of risk factors increases risk of thromboembolic events in patients with nonvalvular atrial fibrillation. Circ J 70: 651-656.

18. Gage BF, Waterman AD, Shannon W, Boechler M, Rich MW, et al. (2001) Validation of clinical classification schemes for predicting stroke: results from the National Registry of Atrial Fibrillation. JAMA 285: 2864-2870.

19. Parikh MG, Aziz Z, Krishnan K, Madias C, Trohman RG, et al. (2012) Usefulness of transesophageal echocardiography to confirm clinical utility of CHA2DS2-VASc and CHADS2 scores in atrial flutter. Am J Cardiol 109: 550-555.

20. Sa T, Sargento-Freitas J, Pinheiro V, Martins R, Teixeira $\mathrm{R}$, et al. (2013) CHADS(2) and CHA(2)DS(2)VASc scores as predictors of cardioembolic sources in secondary stroke prevention. Rev Port Cardiol 32: 373-378.

21. Kleemann T, Becker T, Strauss M, et al. (2009) Prevalence and clinical impact of left atrial thrombus and dense spontaneous echo contrast in patients with atrial fibrillation and low CHADS2 score. Eur J Echocardiogr 10: 383-388.

22. Malik R, Alyeshmerni DM, Wang Z, Goldstein SA, Torguson $R$, et al. (2015) Prevalence and predictors of left atrial thrombus in patients with atrial fibrillation: is transesophageal echocardiography necessary before cardioversion? Cardiovasc Revasc Med 16: 12-14.

23. Nair CK, Holmberg MJ, Aronow WS, et al. (2009) Thromboembolism in patients with atrial fibrillation with and without left atrial thrombus documented by transesophageal echocardiography. Am J Ther 16: 385-392.

24. Chung H, Lee BK, Min PK, Eui-Young Choi, Young Won Yoon, et al. (2016) Left Ventricular Filling Pressure as Assessed by the E/e' Ratio Is a Determinant of Atrial Fibrillation Recurrence after Cardioversion. Yonsei medical journal 57: 64-71.

25. Efremidis M, Alexanian IP, Oikonomou D, Manolatos D, Letsas KP, et al. (2009) Predictors of atrial fibrillation recurrence in patients with long-lasting atrial fibrillation. Can J Cardiol 25: 119-124.

26. Van Noord T, Crijns HJ, van den Berg MP, Dirk J Van Veldhuisen, Isabelle C Van Gelder, et al. (2005) Pretreatment with ACE inhibitors improves acute outcome of electrical cardioversion in patients with persistent atrial fibrillation. BMC Cardiovasc Disord 5: 3.

27. Boriani G, Diemberger I, Biffi M, Domenichini G, Martignani C, et al. (2007) Electrical cardioversion for persistent atrial fibrillation or atrial flutter in clinical practice: predictors of long-term outcome. Int J Clin Pract 61: 748-756.

28. Marchese P, Bursi F, Delle Donne G, Malavasi V, Casali E, et al. (2011) Indexed left atrial volume predicts the recurrence of non-valvular atrial fibrillation after successful cardioversion. Eur J Echocardiogr 12: 214-221.

29. Abu-El-Haija B, Giudici MC (2014) Predictors of long-term maintenance of normal sinus rhythm after successful electrical cardioversion. Clin Cardiol 37: 381-385.

30. Pisters R, Nieuwlaat R, Prins MH, Le Heuzey JY, Maggioni AP, et al. (2012) Clinical correlates of immediate success and outcome at 1-year follow-up of real-world cardioversion of atrial fibrillation: the Euro Heart Survey. Europace 14: 666674.

31. Akdemir B, Altekin RE, Kucuk M, Yanikoğlu A, Karakaş MS, et al. (2013) The significance of the left atrial volume index in cardioversion success and its relationship with recurrence in patients with non-valvular atrial fibrillation subjected to electrical cardioversion: a study on diagnostic accuracy. Anadolu Kardiyol Derg 13: 18-25.

32. Wazni OM, Tsao HM, Chen SA, Chuang HH, Saliba W, et al. (2006) Cardiovascular imaging in the management of atrial fibrillation. J Am Coll Cardiol 48: 2077-2084.

33. Grewal GK, Klosterman TB, Shrestha K, Yarmohammadi H, ZurickAO, et al.(2012) Indications for TEE before cardioversion for atrial fibrillation: implications for appropriateness criteria. JACC Cardiovasc Imaging 5: 641-648.

34. NHMRC. Alcohol guidelines: reducing the health risks. Australian Government National Health and Medical Research Council 2016.

35. Blich M, Edoute Y (2006) Electrical cardioversion for persistent or chronic atrial fibrillation: outcome and clinical factors predicting short and long term success rate. Int J Cardiol 107: 389-394.

36. Dogan A, Akcay S, Karabacak M, Turker Y, Ozaydin M, et al. (2009) The effect of pretreatment with renin-angiotensinaldosterone system blockers on cardioversion success and acute recurrence of atrial fibrillation. Int J Clin Pract 63: 10171023.

37. Kuppahally SS, Foster E, Shoor S, Anthony E Steimle (2009) Short-term and long-term success of electrical cardioversion in atrial fibrillation in managed care system. Int Arch Med 2: 39.

38. Frick M, Frykman V, Jensen-Urstad M, Ostergren J, Rosenqvist M, et al. (2001) Factors predicting success rate and recurrence of atrial fibrillation after first electrical cardioversion in patients with persistent atrial fibrillation. Clin Cardiol 24: 238-244.

39. Raitt MH, Volgman AS, Zoble RG, Charbonneau L, Padder FA, et al. (2006) Prediction of the recurrence of atrial fibrillation 
after cardioversion in the Atrial Fibrillation Follow-up Investigation of Rhythm Management (AFFIRM) study. Am Heart J 151: 390-396.

40. Van Gelder IC, Crijns HJ, Van Gilst WH, Verwer R, Lie KI, et al. (1991) Prediction of uneventful cardioversion and maintenance of sinus rhythm from direct-current electrical cardioversion of chronic atrial fibrillation and flutter. Am J Cardiol 68: 41-46.

41. Dittrich HC, Erickson JS, Schneiderman T, Blacky AR, Savides T, et al. (1989) Echocardiographic and clinical predictors for outcome of elective cardioversion of atrial fibrillation. Am J Cardiol 63: 193-197.

42. Dalzell GW, Anderson J, AdgeyAA(1991) Factors determining success and energy requirements for cardioversion of atrial fibrillation: revised version. Q J Med 78: 85-95.

43. Djousse L, Levy D, Benjamin EJ, Blease SJ, Russ A, et al. (2004) Long-term alcohol consumption and the risk of atrial fibrillation in the Framingham Study. Am J Cardiol 93: 710713.

44. Patel DA, Lavie CJ, Milani RV, Sangeeta Shah, Yvonne Gilliland, et al. (2009) Clinical implications of left atrial enlargement: a review. Ochsner J 9: 191-196.

45. Watson T, Shantsila E, Lip GY (2009) Mechanisms of thrombogenesis in atrial fibrillation: Virchow's triad revisited.
Lancet 373: 155-166.

46. Wysokinski WE, Ammash N, Sobande F, Kalsi H, Hodge D, et al. (2010) Predicting left atrial thrombi in atrial fibrillation. Am Heart J 159: 665-671.

47. Airaksinen KE, Gronberg T, Nuotio I, Nikkinen M, Ylitalo A, et al. (2013) Thromboembolic complications after cardioversion of acute atrial fibrillation: the FinCV (Finnish CardioVersion) study. J Am Coll Cardiol 62: 1187-1192.

48. Decker JM, Madder RD, Hickman L, Victor Marinescu, Anna Marandici, et al. (2001) CHADS (2) score is predictive of left atrial thrombus on precardioversion transesophageal echocardiography in atrial fibrillation. Am J Cardiovasc Dis 1:159-165.

49. Puwanant S, Varr BC, Shrestha K, Hussain SK, Tang WH, et al. (2009) Role of the CHADS2 score in the evaluation of thromboembolic risk in patients with atrial fibrillation undergoing transesophageal echocardiography before pulmonary vein isolation. J Am Coll Cardiol 54: 2032-2039.

50. Yarmohammadi H, Varr BC, Puwanant S, Elizabeth Lieber, Sarah J. Williams, et al. (2012) Role of CHADS2 score in evaluation of thromboembolic risk and mortality in patients with atrial fibrillation undergoing direct current cardioversion (from the ACUTE Trial Substudy). Am J Cardiol 110: 222226.
Copyright: (02017 Callan Gavaghan. This is an open-access article distributed under the terms of the Creative Commons Attribution License, which permits unrestricted use, distribution, and reproduction in any medium, provided the original author and source are credited. 